\title{
Observation of low-temperature object by phase-contrast x-ray imaging: Nondestructive imaging of air clathrate hydrates at $233 \mathrm{~K}$
}

\author{
Satoshi Takeya ${ }^{\text {a) }}$ and Kazumasa Honda \\ National Institute of Advanced Industrial Science and Technology (AIST), Central 5, 1-1-1, Higashi, Tsukuba, \\ Ibaraki 305-8565, Japan \\ Akio Yoneyama and Yasuharu Hirai \\ Advanced Research Laboratory, Hitachi Ltd., Hatoyama, Saitama 350-0395, Japan \\ Junichi Okuyama and Takeo Hondoh \\ Institute of Low Temperature Science, Hokkaido University, N19 W8, Sapporo 060-0819, Japan \\ Kazuyuki Hyodo \\ Institute of Materials Science, High Energy Accelerator Research Organization, Tsukuba, Ibaraki 305-0801, \\ Japan \\ Tohoru Takeda \\ Institute of Clinical Medicine, University of Tsukuba, Ibaraki 305-8575, Japan
}

(Received 20 February 2006; accepted 27 March 2006; published online 26 May 2006)

\begin{abstract}
A cryochamber and a liquid cell that are designed for nondestructive three dimensional observations and arranged in a two-crystal x-ray interferometer expand the use of phase-contrast x-ray imaging that could only be performed at room temperature in previous studies to a new temperature range of $190 \mathrm{~K}$ to room temperature. The methyl acetate in the liquid cell prevents undesirable sample outline contrasts and enables internal observations. Both a nondestructive observation and a highly accurate absolute density of the materials under low-temperature conditions can be obtained with a single measurement using this new technique. A three dimensional x-ray computed tomography (x-ray CT) of the air clathrate hydrate in the hexagonal ice drilled from Dome Fuji in Antarctica is shown, and the density of the air hydrate is estimated to be $0.937(3) \mathrm{g} / \mathrm{cm}^{3}$ at $233 \mathrm{~K}$. (C) 2006 American Institute of Physics. [DOI: 10.1063/1.2200751]
\end{abstract}

\section{INTRODUCTION}

Biological soft tissues and inorganic materials, which consist of mainly carbon, nitrogen, oxygen, and hydrogen atoms, are difficult to observe with conventional x-ray transmission imaging, but are possible by phase-contrast $\mathrm{x}$-ray imaging since the light elements have phase-shift cross sections that are approximately 1000 times larger than their absorption cross sections. ${ }^{1,2}$ Several methods for detecting phase shift using instruments such as a x-ray interferometer, ${ }^{3}$ a crystal analyzer, ${ }^{4}$ and a polychromatic microfocus $\mathrm{x}$-ray ${ }^{5}$ have been proposed. Among these methods, the interferometer based method is suitable for detecting the gradual phase shift and the absolute density of the material. Phase-contrast $\mathrm{x}$-ray computed tomography (x-ray CT) using an x-ray interferometer ${ }^{6}$ is considered to be a powerful tool for the nondestructive observation of the inner texture of biological $^{7,8}$ and inorganic materials. However, the observations of the inner texture are disturbed by an undesirable sample outline contrast that occurs from the steep phase shifts caused by density difference between the sample and atmosphere of the sample. Therefore, the application of phase-contrast $\mathrm{x}$-ray imaging using $\mathrm{x}$-ray interferometer becomes difficult without any buffer material that is necessary for the observations, such as water for biological soft tissues.

${ }^{\text {a)} E l e c t r o n i c ~ m a i l: ~ s . t a k e y a ~ @ a i s t . g o . j p ~}$
Phase-contrast $\mathrm{x}$-ray imaging with a two-crystal $\mathrm{x}$-ray interferometer was developed and assures a large sample observation area. ${ }^{9,10}$ As a result, the technique can be applied for larger biological objects. In addition, the wide sample space allows observations under different conditions using sample chambers even though the optical configuration is complicated compared to the conventional x-ray transmission imaging technique.

Clathrate hydrates are inclusion compounds consisting of a hydrogen-bonded crystal of water molecules with cages that contain gas molecules. ${ }^{11}$ Most of the clathrate hydrates are only stable under the conditions of low temperature or high pressure. Air hydrate is one of the clathrate hydrates containing air $\left(\mathrm{N}_{2}, \mathrm{O}_{2}\right.$, and other small amounts of gas molecules) in the cage structures. ${ }^{12}$ The measurements of the air hydrates are essential for reconstructing the climates over the last several hundred thousand years because the gas concentration measurements that are mainly obtained from the air hydrate in deep ice cores provide an important source for a paleoatmosphere. ${ }^{13}$ However, discovery of air hydrate in ice cores had been difficult even though their existence had been predicted. ${ }^{14}$ The gas hydrate and ice have an equivalent optical reflective index and it made it difficult to observe air hydrates within ice by an optical microscope. ${ }^{15}$ The identification of a gas hydrate with ice or water using a conventional 


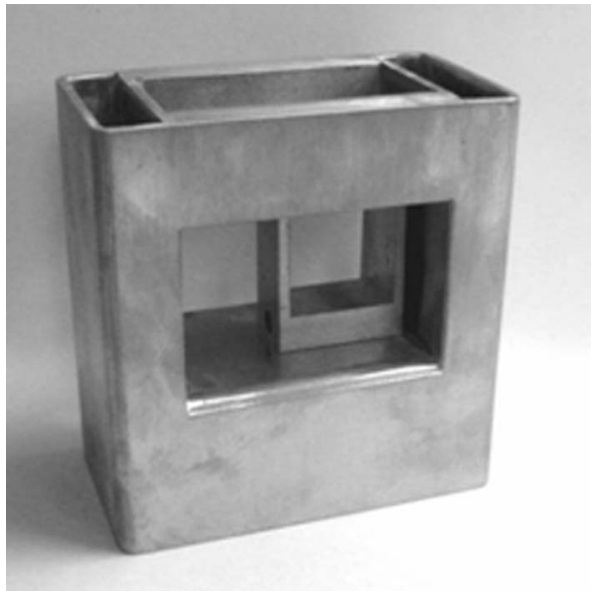

FIG. 1. Photograph of the sample chamber. Only the parts made by brass are shown. The larger part is the cryochamber, and the smaller part that appears on the inside is the liquid cell.

$\mathrm{x}$-ray transmission imaging technique has also been very difficult because both lattice structures are formed by water molecules. ${ }^{16-18}$

In this article, we report a method for observing the air hydrates using the phase-contrast $\mathrm{x}$-ray imaging system equipped with a newly designed sample chamber to use in low-temperature conditions. The undesirable sample outline contrast was controlled by a liquid, which does not freeze even under low-temperature conditions. The technique will allow nondestructive three dimensional observations of not only the air hydrate but also any clathrate hydrates with ice or water. This technique can also be applied for in situ observations of biological and inorganic materials under lowtemperature conditions.

\section{SAMPLE CHAMBER}

The sample chamber was designed for phase-contrast $\mathrm{x}$-ray imaging experiments by synchrotron radiation under low-temperature conditions. Figure 1 shows a photograph of the sample chamber consisting of a cryochamber and a liquid cell. A coolant supplying system could cause mechanical vibrations during x-ray exposure, thus it was not attached to the chamber. The cross section of the sample chamber is shown in Fig. 2.

The cryochamber was composed of a $60 \times 110$ $\times 115 \mathrm{~mm}^{3} \mathrm{U}$-shaped brass square tube containing a coolant such as liquid nitrogen $\left(\mathrm{N}_{2}\right)$ or a mixture of dry ice and ethanol $\left(\mathrm{C}_{2} \mathrm{H}_{5} \mathrm{OH}\right)$. An insulating material covered the chamber and kept the temperature inside the chamber below $220 \mathrm{~K}$ for more than several hours without having to supply any additional coolants. Two x-ray windows made of polyvinyl chloride with a thickness of $0.4 \mathrm{~mm}$ were put into the insulating material at both ends of the cryochamber. The size of these windows was adjusted to $60 \times 30 \mathrm{~mm}^{2}$ so that the object $\mathrm{x}$-ray beam and the reference $\mathrm{x}$-ray beam could go through them. The windows were composed of a three-layer structure where each layer was filled with dry Ar gas, and this structure prevented condensation from occurring on the windows due to the difference between the room temperature at around $295 \mathrm{~K}$ and the low temperature in the chamber.
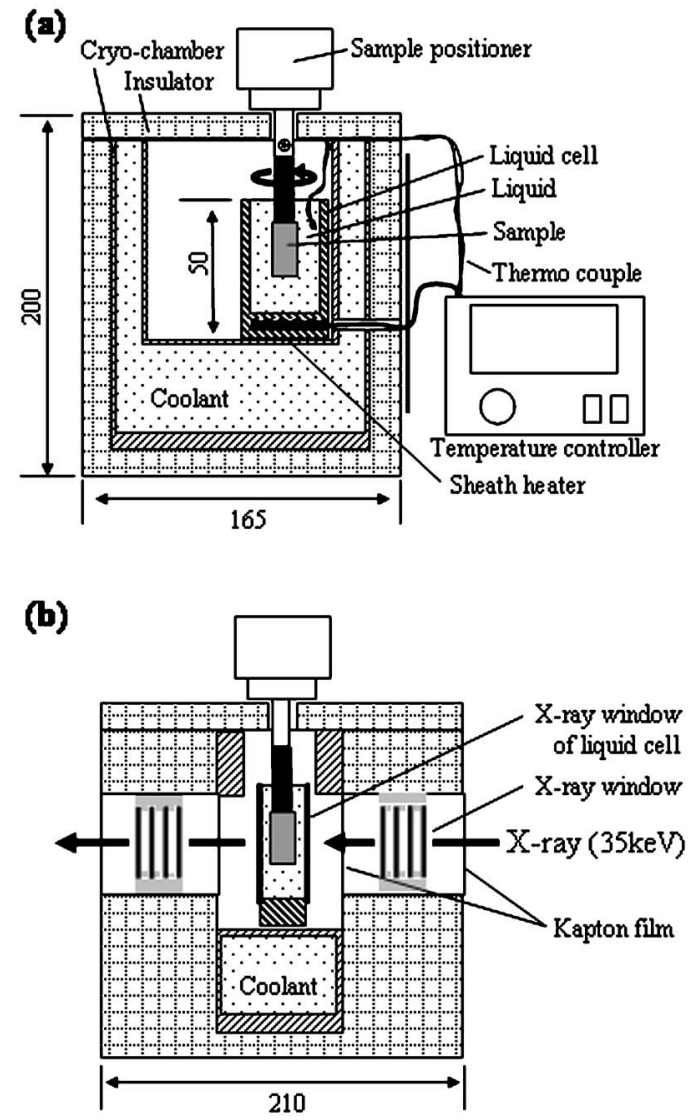

FIG. 2. Cross sections of the sample chamber. (a) Schematic view of the sample chamber perpendicular to the direction of x-ray radiation. (b) Schematic view of the sample chamber parallel to the direction of $\mathrm{x}$-ray radiation.

The $20 \times 35 \times 50 \mathrm{~mm}^{3}$ brass liquid cell consisted of two $\mathrm{x}$-ray windows made of polyvinyl chloride each with a thickness of $0.4 \mathrm{~mm}$. A sheath heater was attached to the bottom of the cell to control the temperature of the liquid that was introduced into the cell, and a thermocouple was attached to the top of the cell to measure the temperature of the liquid. The refractive index of the liquid can be adjusted to almost the same value as the average refractive index of the sample to prevent undesirable sample outline contrasts from appearing on the reconstructed CT images. ${ }^{19}$ Note that the type of liquid material can be selected based on the density of the objective sample and the experimental temperature condition. Therefore, methyl acetate $\left(\mathrm{C}_{3} \mathrm{H}_{6} \mathrm{O}_{2}\right)$ was selected as the liquid for this study because the density of methyl acetate is $0.928 \mathrm{~g} / \mathrm{cm}^{3}$ at $298 \mathrm{~K}$, which is equivalent to that of the hexagonal ice $\left(0.917 \mathrm{~g} / \mathrm{cm}^{3}\right.$ at $\left.273 \mathrm{~K}\right)$. Additionally, methyl acetate can be kept at a liquid state even under lowtemperature conditions since its melting point is $175 \mathrm{~K}$. Based on the above conditions, we were able to obtain the air hydrate measurements in the hexagonal ice.

\section{EXPERIMENTAL PROCEDURE}

A mixture of dry ice and ethanol was introduced into the cryochamber, and the cryochamber was set in the sample position of the separated-type x-ray interferometer (see Fig. 3). Then a liquid cell filled with methyl acetate was put in- 


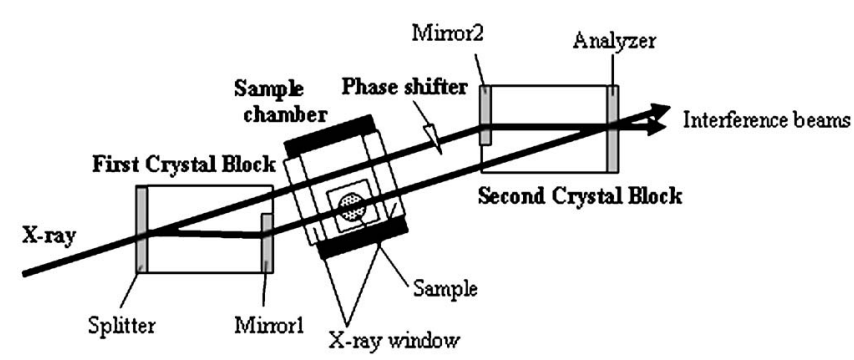

FIG. 3. Top view of the phase-contrast $\mathrm{x}$-ray imaging with skew-symmetric two-crystal $\mathrm{x}$-ray interferometer and the sample chamber.

side the chamber. The temperature of methyl acetate was kept at $223 \mathrm{~K}$ with a temperature deviation of $3 \mathrm{~K}$ during the measurements.

Experiments were performed using a $35 \mathrm{keV}$ monochromatic synchrotron $\mathrm{x}$-ray at the BL-14C1 beam line of the Photon Factory in Tsukuba, Japan. The vertically fan-shaped beam that was emitted from a vertical wiggler was monochromated by a $\mathrm{Si}(220)$ double-crystal monochromator, expanded horizontally by an asymmetric crystal, and input to an imaging system. Measurements were performed by fringe scanning method of three steps. One of the generated interface patterns was detected by a charge-coupled device (CCD)-based sensor $\left(36 \times 36 \mathrm{~mm}^{2}\right.$ field of view with 2048 $\times 2048$ pixels, each $18 \times 18 \mu \mathrm{m}^{2}$ ), and the other by the feedback positioning system. ${ }^{19}$ To obtain a phase-contrast CT image, a cylindrical-shaped ice sample with a diameter of approximately $10 \mathrm{~mm}$ and a length of $20 \mathrm{~mm}$ (see Fig. 4) was placed into a cell filled with methyl acetate and rotated at $1.20^{\circ}$ steps (150 projections). The measurements of projection phase maps (spatial distribution of phase shift caused by the sample) were performed by fringe scanning method including background subtraction that was mentioned fully in a previous paper. ${ }^{20}$ The feedback positioning system operated successfully during the measurement, suppressing the phase fluctuation to within $\pi / 15$.

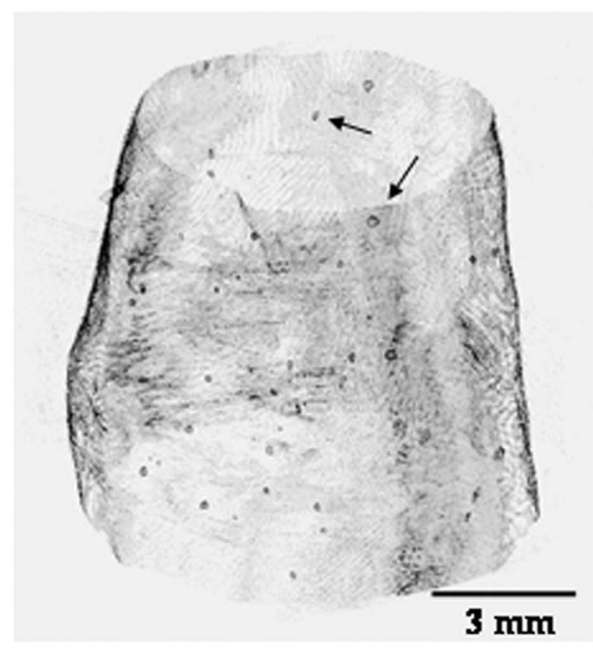

FIG. 4. Three dimensional (3D) image of the spheroid-shaped ice sample including air hydrate crystals measured by the phase-contrast x-ray imaging technique. The dark gray circles in the ice sample indicate the areas where the densities are higher than that of the surrounding ice, which correspond to air hydrate crystals. The internal part of the ice was made transparent to show the air hydrate more clearly.

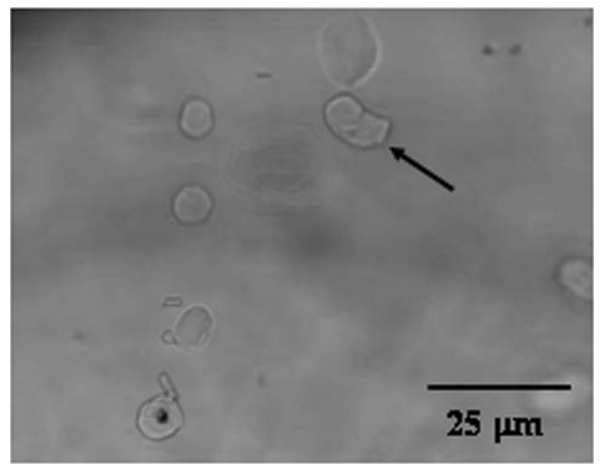

FIG. 5. Optical image of a section of ice sample including air hydrate crystals measured by a microscope. The thickness of the sample was reduced to $10 \mathrm{~mm}$ for the observation without dissociation of air hydrates in a cold room at $-20^{\circ} \mathrm{C}$.

\section{X-RAY IMAGING}

Figure 4 shows a three dimensional image of the ice core sample that was drilled from a $1775.8 \mathrm{~m}$ depth of Dome Fuji in Antarctica. ${ }^{21}$ The figure shows that there are many particles in the ice sample, which correspond to the areas where the densities are higher than that of the surrounding ice. The optical image in Fig. 5 shows that the air hydrate crystals are randomly distributed in the ice sample. Although the absolute value of the density of the air hydrate has not been determined yet even by the x-ray diffraction method, the optical Becke test indicates that the density of the air hydrate is slightly higher than that of the hexagonal ice. ${ }^{22}$ Therefore, we can conclude that the particles in the ice core sample are air hydrate crystals.

This new technique makes it possible to determine the difference in the densities between the air hydrate crystal and ice. Figure 6 shows the density differences between the air hydrate crystal and ice plotted against the size of the air hydrate crystal in the sample shown in Fig. 4. The average density of the air hydrate is estimated to be $13.6 \mathrm{mg} / \mathrm{cm}^{3}$

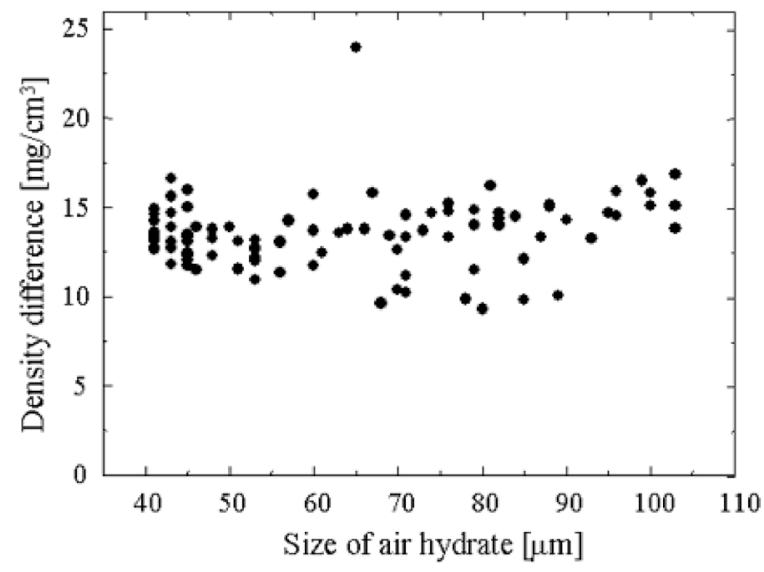

FIG. 6. Density difference between the air hydrate crystal and the surrounding ice plotted against the size of the air hydrate crystal. The size of the air hydrate crystal expresses the diameter, which was estimated by a spherical approximation using the voxel size of $18 \times 18 \times 18 \mu \mathrm{m}^{3}$. Only the air hydrates, which are larger than six voxels in volume size, were used for the analysis. The density difference of one of the data points is much higher than that of the other points, thus it might not be an air hydrate but another kind of hydrate such as a hydrate of sulfate salt as reported in Ref. 26. 
higher than that of the surrounding hexagonal ice. The figure also shows that the density differences between the air hydrate and the surrounding ice have a deviation of about $6 \mathrm{mg} / \mathrm{cm}^{3}$. Thus, the density difference is estimated to be $14 \pm 3 \mathrm{mg} / \mathrm{cm}^{3}$. On the other hand, the density of the ice at $233 \mathrm{~K}$ is estimated to be $0.923 \mathrm{~g} / \mathrm{cm}^{3}$ by the experimental result of $\mathrm{x}$-ray diffraction. ${ }^{23}$ Therefore, we can conclude that the density of the air hydrate is $0.937(3) \mathrm{g} / \mathrm{cm}^{3}$ at $233 \mathrm{~K}$. The density deviation of each air hydrate crystal would be caused by a crystallographic difference such as the lattice constant or the cage occupancy of the air hydrate crystals as reported in the previous studies. ${ }^{24,25} \mathrm{~A}$ deviation of only $0.05 \AA$ in the lattice constant of an air hydrate crystal causes a deviation of about $10 \mathrm{mg} / \mathrm{cm}^{3}$ in the density for the same cage occupancy condition.

As shown in this article, we can perform not only a nondestructive observation of a light element crystal but also the absolute density mapping of materials under lowtemperature condition using phase-contrast $\mathrm{x}$-ray imaging equipped with the cryochamber. The phase-contrast x-ray imaging also allows the application of nondestructive observations on other materials under different temperature conditions. Furthermore, the high density resolution of the experimental system makes it possible to detect not only nondestructive images of the internal texture but also crystallographic differences such as the lattice constant. Thus, the experimental technique reported in this study can also be applied to the imaging of temperature induced phase transition or the compositional change of inorganic materials.

\section{ACKNOWLEDGMENTS}

We would like to thank J. Itoh of Itoh Keiki Kogyo Corp. for his technical assistance on designing the chamber. We would also like to thank all the participants of the Japan Antarctic Research Expedition (JARE) for the drilling, field work, and ice sampling. One of the authors (S.T.) would like to express his gratitude to T. Uchida and S. Jin of Hokkaido University, W. Shimada of Toyama University, and Y. Gotoh, H. Fujihisa, and J. Nagao of AIST for their valuable comments. This study was carried out under Proposal Nos.
2005S2-001 and 2005G294, and was approved by the High Energy Accelerator Research Organization.

${ }^{1}$ A. Momose and J. Fukuda, Med. Phys. 22, 375 (1995).

${ }^{2}$ T. Takeda, A. Momose, Y. Itai, J. Wu, and K. Hirano, Acad. Radiol. 2, 799 (1995).

${ }^{3}$ U. Bonse and M. Hart, Appl. Phys. Lett. 6, 155 (1965).

${ }^{4}$ J. Davis, D. Gao, T. E. Gureyev, A. W. Stevenson, and S. W. Wilkins, Nature (London) 373, 595 (1995).

${ }^{5}$ S. W. Wilkins, T. E. Gureyev, D. Gao, A. Pogany, and A. W. Stevenson, Nature (London) 384, 335 (1996).

${ }^{6}$ A. Momose, Nucl. Instrum. Methods Phys. Res. A 352, 622 (1995).

${ }^{7}$ A. Momose and T. Takeda, Nat. Med. 2, 852 (1996).

${ }^{8}$ T. Takeda, A. Momose, K. Hirano, S. Haraoka, T. Watanabe, and Y. Itai, Radiology 214, 298 (2000).

${ }^{9}$ A. Yoneyama, A. Momose, E. Seya, K. Hirano, T. Takeda, and Y. Itai, Rev. Sci. Instrum. 70, 4582 (1999).

${ }^{10}$ A. Yoneyama, T. Takeda, Y. Tsuchiya, J. Wu, T. T. Lwin, A. Koizumi, K. Hyodo, and Y. Itai, Nucl. Instrum. Methods Phys. Res. A 523, 217 (2004).

${ }^{11}$ E. D. Sloan, Clathrate Hydrate of Natural Gases, 2nd ed., (Marcel Dekker, New York, 1998).

${ }^{12}$ H. Shoji and C. C. Langway, Nature (London) 298, 548 (1982).

${ }^{13}$ F. Pauer, J. Kipfstuhl, and W. F. Kuhs, Geophys. Res. Lett. 28, 969 (1995)

${ }^{14}$ S. L. Miller, Science 165, 489 (1969).

${ }^{15}$ T. Uchida, W. Shimada, T. Hondoh, S. Mae, and N. I. Barkov, Appl. Opt. 34, 5746 (1995).

${ }^{16}$ S. Jin, S. Takeya, J. Hayashi, J. Nagao, Y. Kamata, T. Ebinuma, and H. Narita, Jpn. J. Appl. Phys. 43, 5673 (2004).

${ }^{17}$ S. Jin, S. Takeya, J. Hayashi, J. Nagao, Y. Kamata, T. Ebinuma, and H. Narita, Proceedings of the Fifth International Conference on Gas Hydrates (Tapir Academic, Trondheim, 2005), Vol. 2, p. 638.

${ }^{18}$ A. Gupta, E. D. Sloan, T. J. Kneafsey, L. Tomutsa, and G. Moridis, Proceedings of the Fifth International Conference on Gas Hydrates (Tapir Academic, Trondheim, 2005), Vol. 2, p. 422.

${ }^{19}$ A. Momose, Nucl. Instrum. Methods Phys. Res. A 352, 622 (1995).

${ }^{20}$ A. Yoneyama, T. Takeda, Y. Tsuchiya, J. Wu, T. T. Lwin, and K. Hyodo, Proceedings of the Eight International Conference Synchrotron Radiation Instrumentation (SRI2003), edited by T. Warwick, J. Arthur, H. A. Padmore, and J. Stohr [AIP Conf. Proc.705, 1299 (2004)].

${ }^{21}$ O. Watanabe, K. Kamiyama, H. Motoyama, Y. Fujii, H. Shoji, and K. Satowa, Ann. Glaciol. 29, 176 (1999).

${ }^{22}$ T. Hondoh, H. Anzai, A. Goto, S. Mae, A. Higashi, and C. C. Langway, J. Inclusion Phenom. Mol. Recognit. Chem. 8, 17 (1990).

${ }^{23}$ K. Röttger, A. Endriss, J. Ihringer, S. Doyle, and W. F. Kuhs, Acta Crystallogr., Sect. B: Struct. Crystallogr. Cryst. Chem. B50, 644 (1994).

${ }^{24}$ S. Takeya, H. Nagaya, T. Matsuyama, T. Hondoh, and V. Ya. Lipenkov, J. Phys. Chem. B 104, 668 (2000).

${ }^{25}$ T. Ikeda-Fukazawa, T. Hondoh, H. Fukazawa, and S. Mae, J. Geophys. Res. D 106, 17799 (2001).

${ }^{26}$ H. Ohno, M. Igarashi, and T. Hondoh, Earth Planet. Sci. Lett. 232, 171 (2005). 